\title{
Large Intramural Aortic Hematoma with Intimal Tear
}

\author{
Frédéric Jacques, MD, MSc ${ }^{1}$ Michel Gingras, $\mathrm{MD}^{2} \quad$ Valérie Lafrenière-Bessi, $\mathrm{PhD}^{1}$ ean Perron, $\mathrm{MD}^{1}$ \\ François Dagenais, $\mathrm{MD}^{1}$
}

1 Departments of Cardiac Surgery, Institut Universitaire de Cardiologie et de Pneumologie de Québec-IUCPQ, Quebec, QC, Canada

2 Departments of Medical Imaging, Institut Universitaire de Cardiologie et de Pneumologie de Québec-IUCPQ, Quebec, QC, Canada

\author{
Address for correspondence Frédéric Jacques, MD, Departments of \\ Cardiac Surgery, Institut Universitaire de Cardiologie et de \\ Pneumologie de Québec-IUCPQ, Quebec, QC G1V 4G5, Canada \\ (e-mail: frederic.jacques@criucpq.ulaval.ca).
}

AORTA 2020;8:118-120.
Abstract
Keywords
- aortic intramural hematoma
- dissection
- acute aortic syndrome

A 72-year-old man presented with excruciating epigastric pain. A chest computed tomography angiography revealed an aortic intramural hematoma. A filling defect within the distal ascending aorta was noted. Images of an intramular hematoma and surgical details of an ascending aortic replacement under deep hypothermic circulatory arrest are provided.
A 72-year-old man presented with excruciating epigastric pain not associated with exercise or trauma. After excluding myocardial ischemia, a chest computed tomography angiography revealed an aortic intramural hematoma (IMH) of $5 \mathrm{~mm}$ in thickness starting at the sinotubular junction (34 mm) and extending circumferentially to the diaphragm (27 mm; - Fig. 1A-C). A filling defect within the distal ascending aorta was present (-Fig. 1A-C).

An ascending aortic replacement was performed under deep hypothermic circulatory arrest. A thrombus covering a small intimal tear was found within the aortic lumen at the distal ascending aorta corresponding to the filling defect (-Fig. 1D). No other intimal tear was found. The hematoma was removed ( - Fig. 1D) to ensure secure proximal and distal anastomoses, no embolization occurred. The patient was discharged on postoperative day 6 without complication.

Disruption of a vasa vasorum within the media or bleeding within the vicinity of a penetrating atherosclerotic ulcer are the mechanisms reported to cause IMH. ${ }^{1,2}$ Minimal intimal tear with secondary thrombus formation is the probable etiology of IMH in this case. Surgeons performing open and received

November 15, 2018

accepted

May 24, 2020
DOI https://doi.org/

$10.1055 / \mathrm{s}-0040-1714058$.

ISSN $2325-4637$.
Copyright $\odot 2020$ by Thieme Medical

Publishers, Inc., 333 Seventh Avenue,

New York, NY 10001, USA.

Tel: +1(212) 760-0888.
License terms

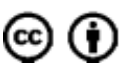



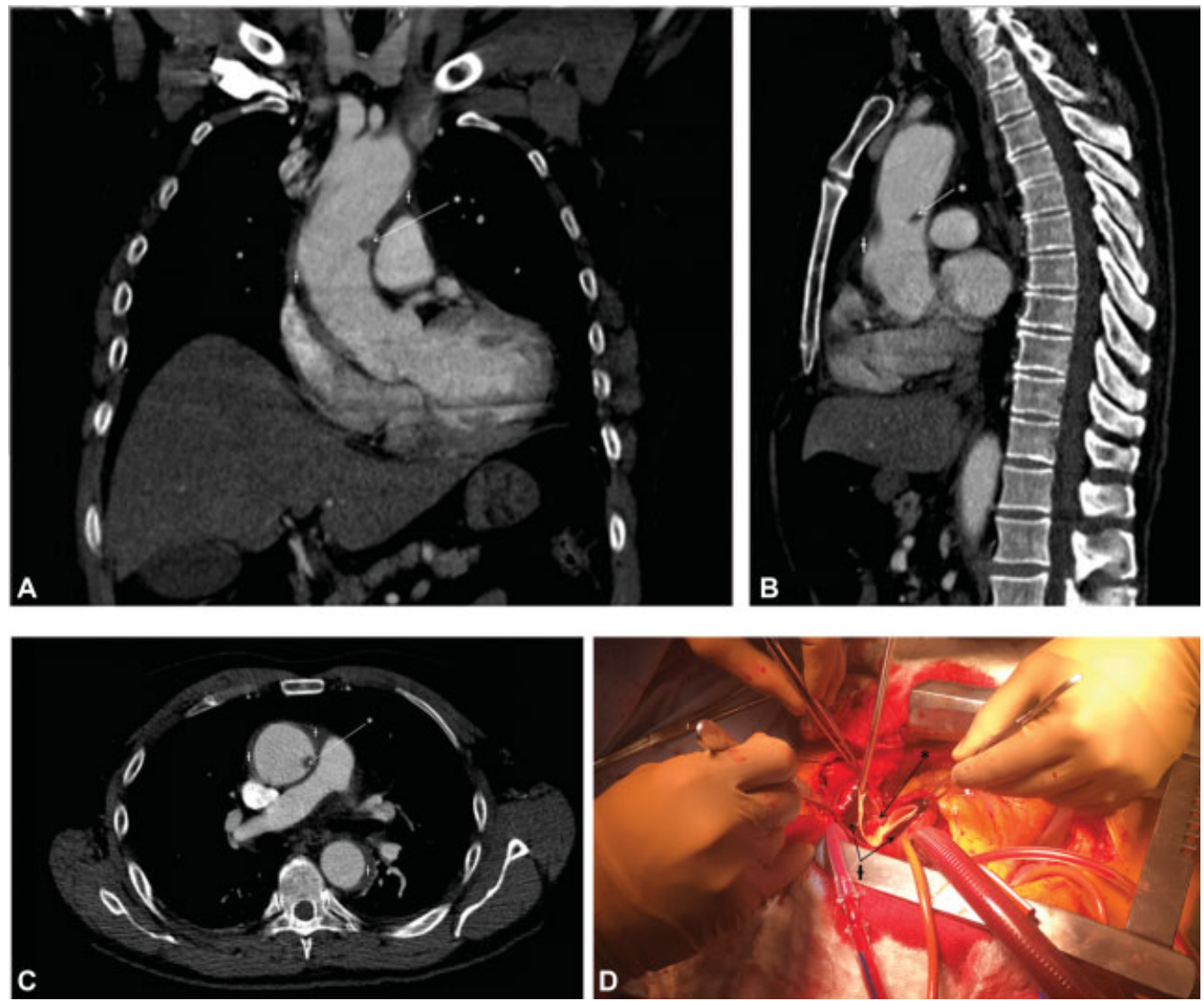

Fig. 1 (A-C) Chest computed tomography angiography revealing an aortic intramural hematoma in intraluminal filling defect. (D) Intraoperative thrombus covering a small intimal tea.

endovascular surgical repair should be aware of this finding and its risks for thromboembolic complications.

\section{Editor's Comments}

Surgeons who operate on intramural hematoma (IMH) cases have long noted that intimal tears are often found at surgery, despite their not being seen on radiographic imaging. This is important because it contradicts the conventional wisdom that IMHs represent rupture of vasa vasorum without connection to the lumenal blood flow. The case reported and illustrated by Jacques and colleagues supports an alternate understanding of etiology and pathophysiology of IMH. That is to say, although IMHs do not demonstrate the intimal flap of typical aortic dissection, they may indeed originate via a tear in the intima of the aorta. (Another possibility is that the IMH originates via rupture of a vasa vasorum and subsequently ruptures through the aortic intimal.)
Funding

None.

Conflict of Interest

The authors declare no conflict of interest related to this article.

Acknowledgments

None.

\section{References}

1 Alomari IB, Hamirani YS, Madera G, Tabe C, Akhtar N, Raizada V. Aortic intramural hematoma and its complications. Circulation 2014;129(06):711-716

2 Sundt TM. Intramural hematoma and penetrating atherosclerotic ulcer of the aorta. Ann Thorac Surg 2007;83(02):S835-S841, discussion S846-S850 
